\title{
FULL SCALE IMPACT TESTS OF AN OVERTOPPING BORE ON A VERTICAL WALL IN THE LARGE WAVE FLUME (GWK) IN HANNOVER
}

\author{
Julien De Rouck ${ }^{1}$, Koen Van Doorslaer ${ }^{1}$, Tom Versluys ${ }^{1}$, Karunya Ramachandran $^{2}$, Stefan \\ Schimmels ${ }^{2}$, Matthias Kudella ${ }^{2}$ and Koen Trouw ${ }^{3}$ \\ To meet up with the requirements of the Flemish Government, the Belgian coastline needs a protection to a storm \\ with a return period of 1000 years. At well-chosen locations, storm walls will be built, and for the structural design of \\ these walls the impact loadings need to be known. Tests have been carried out at full scale in the Grosser Wellen \\ Kanal, to determine the impact loads by overtopping bores. Wave overtopping over the crest of the dike occurs, and \\ the overtopping bore progresses along the horizontal crest of the dike before impacting the storm wall. It is of major \\ importance that such a wall can withstand the impacts. This paper describes the hydraulic process on the crest of the \\ dike, expressed with parameters such as flow depth and flow velocity, and links them to the impact measured on the \\ storm wall. Both pressures and forces are measured, and compared to each other.
}

Keywords: storm wall; overtopping bore; impact; large scale test; pressure; force

\section{INTRODUCTION}

Wave overtopping and how to reduce wave overtopping has been the topic of many research projects throughout the years. Storm walls (see Van Doorslaer et al., 2010a), stilling wave basins (see Geeraerts et al., 2006), parapets (see Van Doorslaer et al. 2010b) and other 'hard' constructions have been studied and for each, a reduction factor has been determined which quantifies how effective the proposed measure is under certain geometrical and hydraulic boundary conditions. The next step in upgrading the safety of coastal towns towards a storm with potentially large hazards, is to investigate the need of such a measure to reduce wave overtopping and selecting the best possible one. For the Belgian Coastline, this step of the process was carried out by the Flemish Government and written down in the Integrated Master Plan of Coastal Safety (see Mertens et al., 2008). The last step now is building the selected safety measures, which can withstand a storm with a return period of 1000 years. Therefor, a good estimation of the impact forces on for example a storm wall located at the end of a dike with promenade at a Belgian coastal town is required. However, the geometrical boundary conditions of such dikes at the Belgian coastline don't allow to find the necessary design formulas in literature.
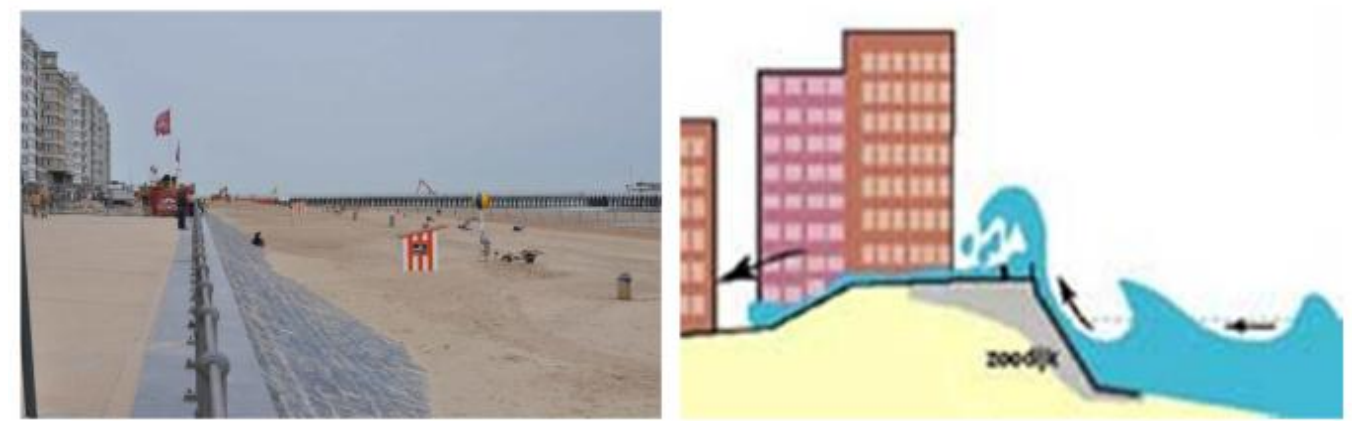

Fig. 1. Typical dike geometry in Belgium, with beach suppletion (left) and without beach suppletion (right)

A typical dike geometry along the Belgian coastline is shown in Fig. 1: a mild sloping sandy beach with at the end a smooth dike with slope 1:2 to $1: 3$, followed by a horizontal promenade.

Before 2004 the water level reached the smooth dike nearly every winter during a storm with rather low return period (Fig. 1, right), leading to large wave overtopping and sometimes even flooding in the low lying city center behind the dikes. To rapidly decrease this risk, an emergency beach suppletion was carried out in 2004 at the most critical locations along the Belgian coastline (Fig. 1, left). The water level near the toe of the dike is now much lower, creating a lower risk of overtopping and a higher safety level in the current situation. Looking at the future sea level rise, and also looking at other locations in the world where the water level in front of the dike is higher, it was decided to work with deep water conditions at the front of the dike in the physical test campaign.

\footnotetext{
${ }^{1}$ Dept. of Civil Engineering, Ghent University, Belgium; koen.vandoorslaer@ugent.be

${ }^{2}$ Forschungszentrum Küste, Hannover, Germany; ramachandran@fzk-nth.de

${ }^{3}$ Ministry of Flemish Community, Coastal Division. Belgium; koen.trouw@mow.vlaanderen.be
} 
The waves overtopping the crest of the dike, progress along the horizontal promenade before having an impact on the storm wall. As was observed during the test campaign, it are no longer waves but an overtopping bore which is impacting the storm wall. No design formulae for this typical situation were found in literature, and a physical model was necessary to provide the designers with input on impact forces of an overtopping bore on a storm wall. In 2010, impact tests started at the wave flume of Ghent University $(\mathrm{L}=30 \mathrm{~m}, \mathrm{~W}=1 \mathrm{~m}, \mathrm{H}=1.20 \mathrm{~m})$ at a scale of $1 / 20$ for several storm walls with different heights and at different locations at the promenade. Later, impact tests on the final wall geometry (wall of $1.2 \mathrm{~m}$ high at $10 \mathrm{~m}$ behind the crest) were carried out for varying hydraulic boundary conditions. The small scale tests were followed by two test campaigns at large scale, one using the Wave Overtopping Simulator (see Steendam et al., 2011), another one carried out in Grosser Wellen Kanal (GWK) in Hannover. A successive test campaign will be carried out in the Hydralab IV program. The overview of all test campaigns was given in Van Doorslaer et al. (2012).

The present paper is dealing with the analysis of the irregular waves of the large scale tests in GWK, Hannover. Some tests with regular waves were also carried out, the get a better understanding of the hydraulics on the crest of the dike and the physical behavior of the impact at the storm walls. Results are described in Ramachandran et al. (2012, a and b).

\section{TEST SET-UP}

A joint research project between Ghent University (Belgium) and Forschüngszentrum Küste (FZK, Germany) was set-up, and large scale tests were carried out in the Large Wave Flume (Grosser Wellen Kanal, GWK) in Hannover, Germany. This wave flume has a length of $300 \mathrm{~m}$, is $5 \mathrm{~m}$ wide and $7 \mathrm{~m}$ high. A dike with slope 1:3 and crest height $6.5 \mathrm{~m}$, constructed of interlocked concrete tiles, was built in the flume to test the stability of the interlocking revetment blocks, see Gier et al. (2012). Since the geometry of this dike was close to what we wanted to test, and since there was only a limited amount of time for carrying out the tests, it was decided to use the dike as it was and win a few weeks of construction time. This also means that some restrictions were faced during the test campaign, from which some important lessons have been learned for the continuation of this project in the Hydralab IV project.

Two storm walls of $1.5 \mathrm{~m}$ and $1.7 \mathrm{~m}$ high were built on the horizontal promenade at $10 \mathrm{~m}$ behind the crest. These storm walls were attached to a steel beam which was connected to the rigid side-walls of the flume and not to the dike itself. The goal of this very stiff structure was to minimize vibrations and other noise in the measurements.

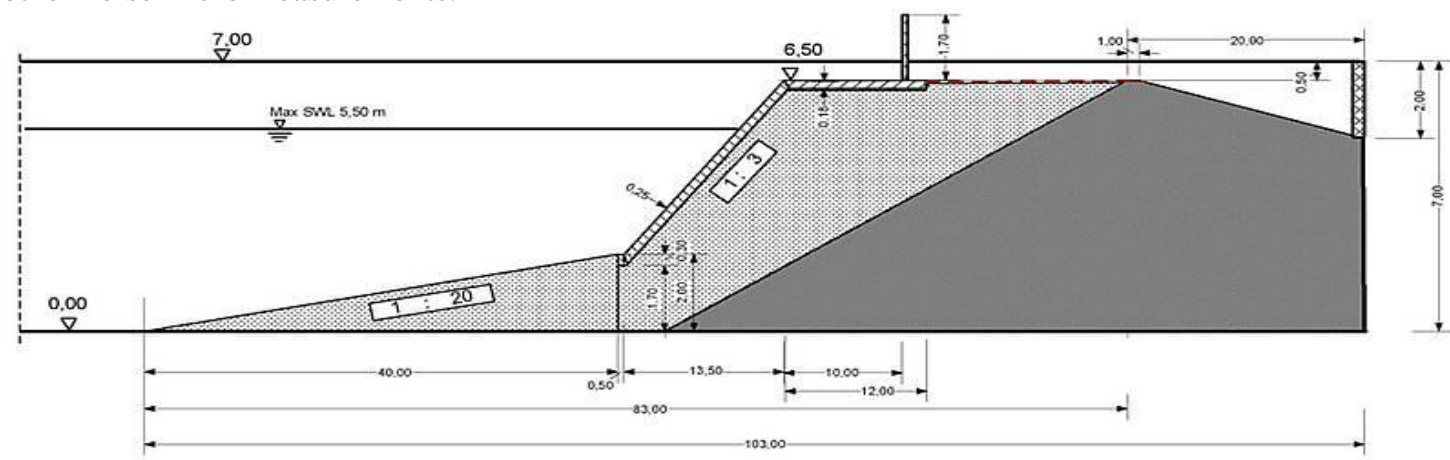

Fig. 2. Set-up in the GWK. Dike with $1: 3$ slope, crest height of $6.5 \mathrm{~m}$ and a promenade of $10 \mathrm{~m}$ followed by a storm wall of $1.7 \mathrm{~m}$ high.

The water level of the tests was $4.5 \mathrm{~m}$ and $5.0 \mathrm{~m}$, giving a crest freeboard of $2 \mathrm{~m}$ respectively $1.5 \mathrm{~m}$. This paper will only deal with the irregular waves (Jonswap Spectrum with $\gamma_{p}=3.3$ ). Wave height $H_{m 0}$ varied from $0.85 \mathrm{~m}$ to $1.5 \mathrm{~m}$, with a wave period $\mathrm{T}_{\mathrm{P}}$ in the range of $6.0 \mathrm{~s}$ to $12.0 \mathrm{~s}$. Behind the storm wall, at the end of the flume, an overtopping basin was installed with 2 pumps pumping the water back towards the flume. Next to the storm walls, some gaps were foreseen (see further discussion), to let the water on the crest of the dike evacuate. The size of the overtopping basin however, was not adapted to this large amount of water which needed to be collected and also the pumps were not strong enough to empty this basin during the tests. The overtopping basin got full quite often. Therefore, the tests were aborted when the overtopping basin was full, or the opposite, when the wave overtopping was too low and no impacts were measured. The design of the crest level, in relation to the maximum achievable water level, the size of the overtopping basin and the capacity of the pumps should be designed more in detail in the future test campaign. 


\section{Measurement equipment}

In this project the incident wave parameters (water level, wave height, wave period), postovertopping characteristics of the bore (flow depth, flow velocity) and impacts on the storm wall (impact forces, impact pressures) were measured at several locations in the flume, on the crest and at the wall respectively. The overtopping discharges and individual overtopping volumes were not recorded in this test campaign.

Starting with the wave flume, 3 sets of resistive wave gauges were installed over the length of the flume. A first set of three gauges near the wave paddle (deep water conditions), a set of four in front of the toe of the dike, and a set of three gauges at $2 / 3^{\text {rd }}$ of the used length of the flume to observe the evolution of the wave parameters over the length of the flume. A wave gauge at the wave paddle is controlling the active wave absorption.

At the crest, several measurement systems were combined in order to first measure as much as possible, and secondly compare the different measurement techniques. All sensors on the crest were continuously storing data at a sampling frequency of $2 \mathrm{kHz}$.

To measure the flow depth of the overtopping bore on the crest, three digital step gauges are installed at different locations on the promenade: at $0.5 \mathrm{~m}, 3.8 \mathrm{~m}$ and $7.9 \mathrm{~m}$ counting from the start of the promenade. A digital step gauge is a PVC rod with in our case a sensor every $2 \mathrm{~cm}$ in height indicating whether it is wet or dry. The highest sensor indicating that it's wet gives you the flow depth. These step gauges could also be used to determine the flow velocity of the overtopping bore. By knowing the exact distance in between two different step gauges, and by the time difference of these two sensors reacting to an incoming overtopping bore, the velocity of this bore in between the two step gauges can be calculated. This method can be verified with video-analysis. At different positions along the crests promenade, video cameras were installed mainly to get a better understanding of the physical behavior of impacts, run-up, splash, etc. A grid with $1 \mathrm{~m}$ interval was painted on the crest promenade. Thereby, the video images can also be used to determine which distance a wave front has covered in a certain time frame, telling you the front velocity of the overtopping bore. A final way to measure velocities of the overtopping bore, was to install a propeller at the same location of each step gauge. After calibration, the rotation of the propeller's blade is linked to the velocity of the overtopping bore at a certain point in the velocity profile over the height of the bore. This easy method was however not working well, since small grains and dirt particles in the water easily blocked the propeller during a test, disturbing the velocity recording. In a future test campaign, it's important to use propellers with a larger housing to avoid blocking by sand particles in the water.

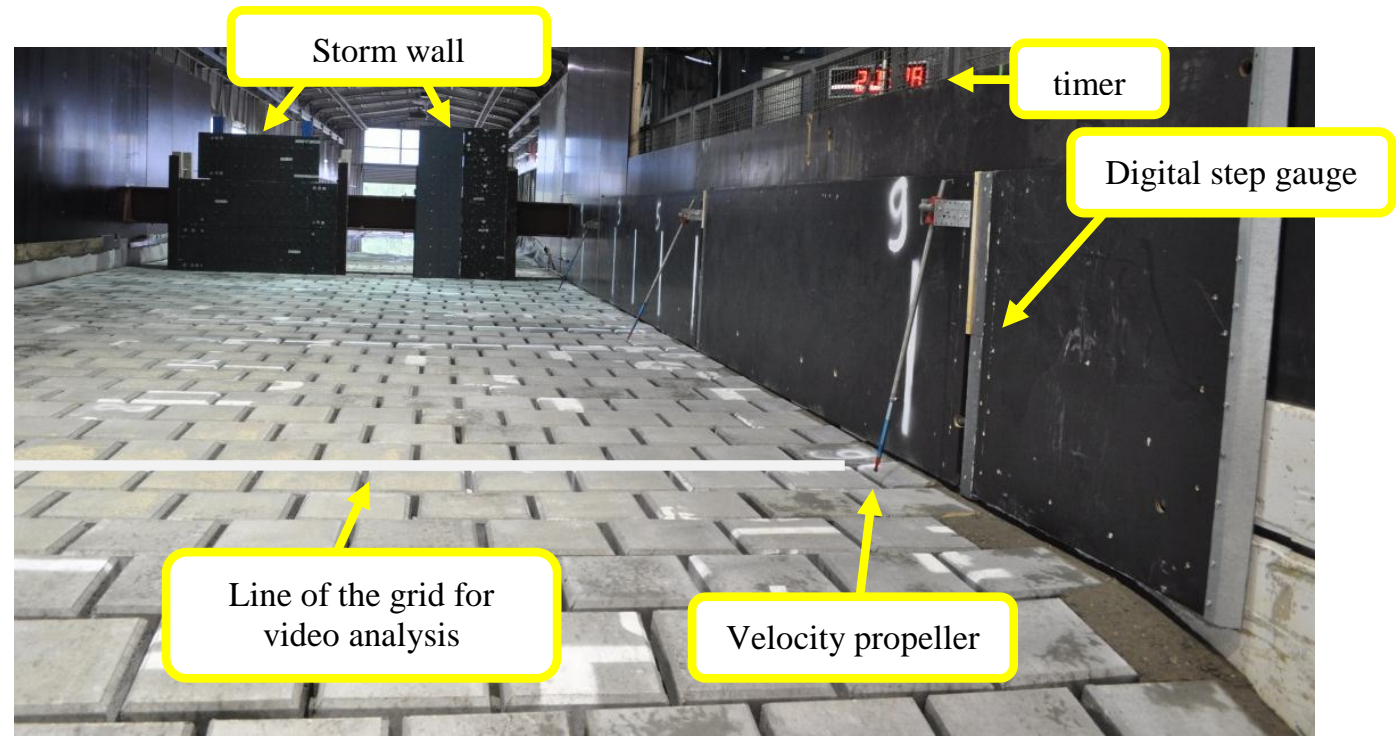

Fig. 3. Overview of the measurement equipment on the $10 \mathrm{~m}$ horizontal promenade.

The last and most intensive location where measurements were conducted, was at the storm wall itself. There were two walls with measurement equipment built at $10 \mathrm{~m}$ behind the crest, as shown in Fig. 3. The left storm wall consists of 3 horizontal aluminium plates with dimensions $1.7 \mathrm{~m} \times 0.5 \mathrm{~m}$, 
$1.7 \mathrm{~m} \times 0.5 \mathrm{~m}$ and $1.3 \mathrm{~m} \times 0.5 \mathrm{~m}$. Each plate was attached to 4 force sensors, located in the corner of each plate. The right storm wall is again split up in 2 parts: a left part to measure pressure and a right part to measure forces. The force transducers are installed at each corner of this right plate. The pressure sensors were installed at 2 vertical rows, each row with 8 sensors and positioned according to Fig. 4. The left row were ABPH sensors, the right row were PDCR sensors, both installed flush mounted on the storm wall.
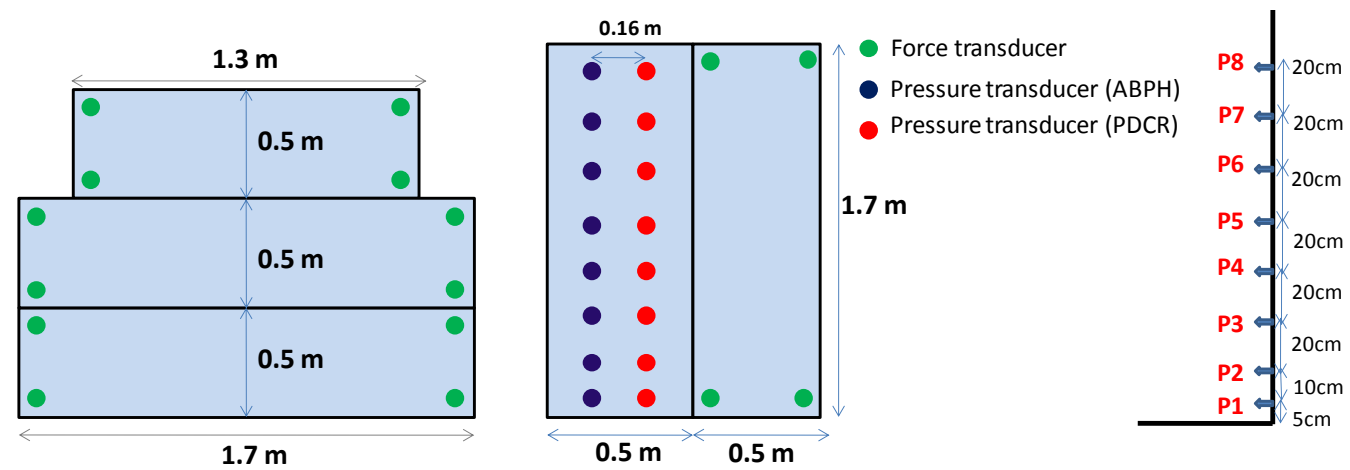

Fig. 4. Installation of force and pressure sensors at the left and right storm wall (left, middle), and their position in height (right).

With this setup, the goal of the research project was not only to link incoming wave parameters, overtopping bore parameters and the impact forces on a storm wall to each other, but also to compare pressure with force measurements, to compare different sensors to measure pressure and finally also to have a better understanding of the force/pressure distribution over the height of the storm wall.

The ABPH sensors however were influenced by temperature variation and forces exerted on the housing of the sensors during the impacts and did not give reliable results. They were further excluded from the analysis, and only the PDCR sensors were used for comparison with force measurements.

The current paper will deal with the wave impacts caused by overtopping bores of irregular waves. Also regular waves have been run during this research project. Those results and a comparison between the pressures and the forces have been described by Ramachandran et al. (2012, a and b).

\section{Hydrodynamic processes of an impacting bore}

To have a better understanding of the kinematics of the overtopping bore impacting the storm wall, a principal sketch is shown in Fig. 5.

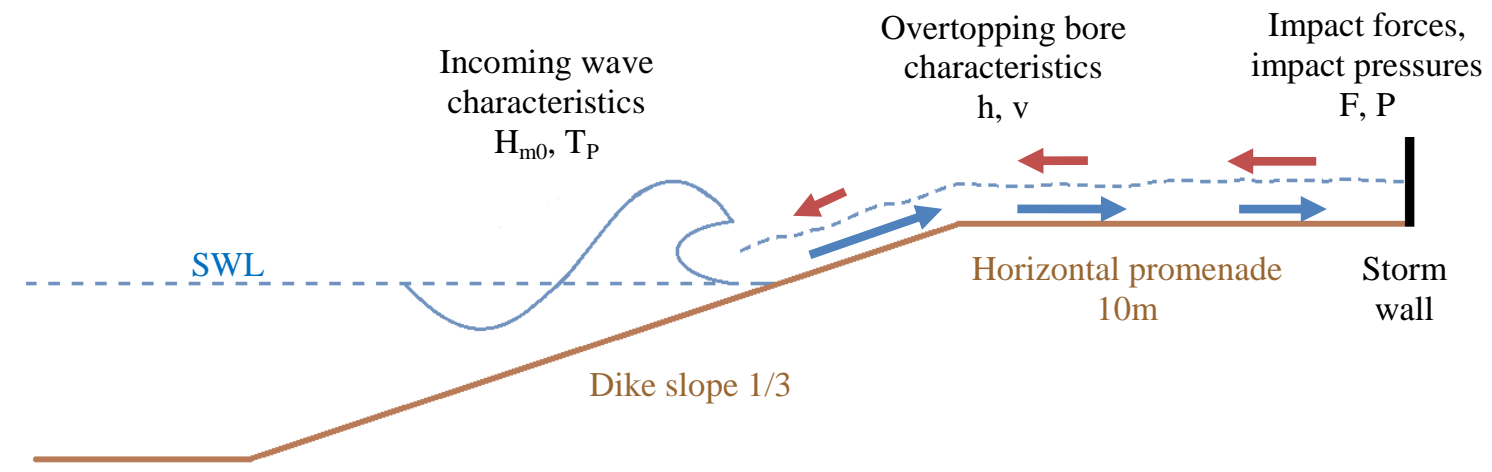

Fig. 5. Hydrodynamic processes associated with the impact of the overtopping bore on the dike crest

Due to the low crest freeboard, wave overtopping occurs. The overtopping bore has a certain flow depth and horizontal velocity while progressing towards the storm wall. After an impact has occurred, this incoming overtopping bore reflects and progresses back towards the sea. If at that moment, a new overtopping event occurs the incoming and reflected bore meet each other. A reduction in flow velocity of the incoming wave and an increased flow depth. The impact on the storm wall reduces, since a part of the energy of the incoming overtopping bore is already lost in the collision with the reflected bore. 
In a first test set-up, a continuous storm wall was created by closing the gaps in between the storm walls with timber plates. Due to a lot of wave overtopping, there was no time for the water on the promenade to evacuate, leading to a residual water layer of some tens of centimeters (up to $50 \mathrm{~cm}$ ). This was a high damping factor on the wave impacts measured on the storm wall. However, in reality, a 3D situation, the water will also evacuate along the sides with higher possibility of an empty crest by the time the next wave overtops the structure. Also since the wave impact will be higher on an empty crest, and the worst-case scenario needed to be investigated, it was decided to remove the timber plates and let the water evacuate through the gaps. A $10 \mathrm{~cm}$ timber plate was left at the sides of the plates with measuring equipment, trying to minimize the side effects which could occur if water is passing through these gaps. In Ramachandran et al. (2012 a), the results of some tests (regular waves) with and without residual water layer have been described and some pictures of the set up with closed walls are shown. In this paper, only the set up with gaps (see Fig. 6) is discussed.

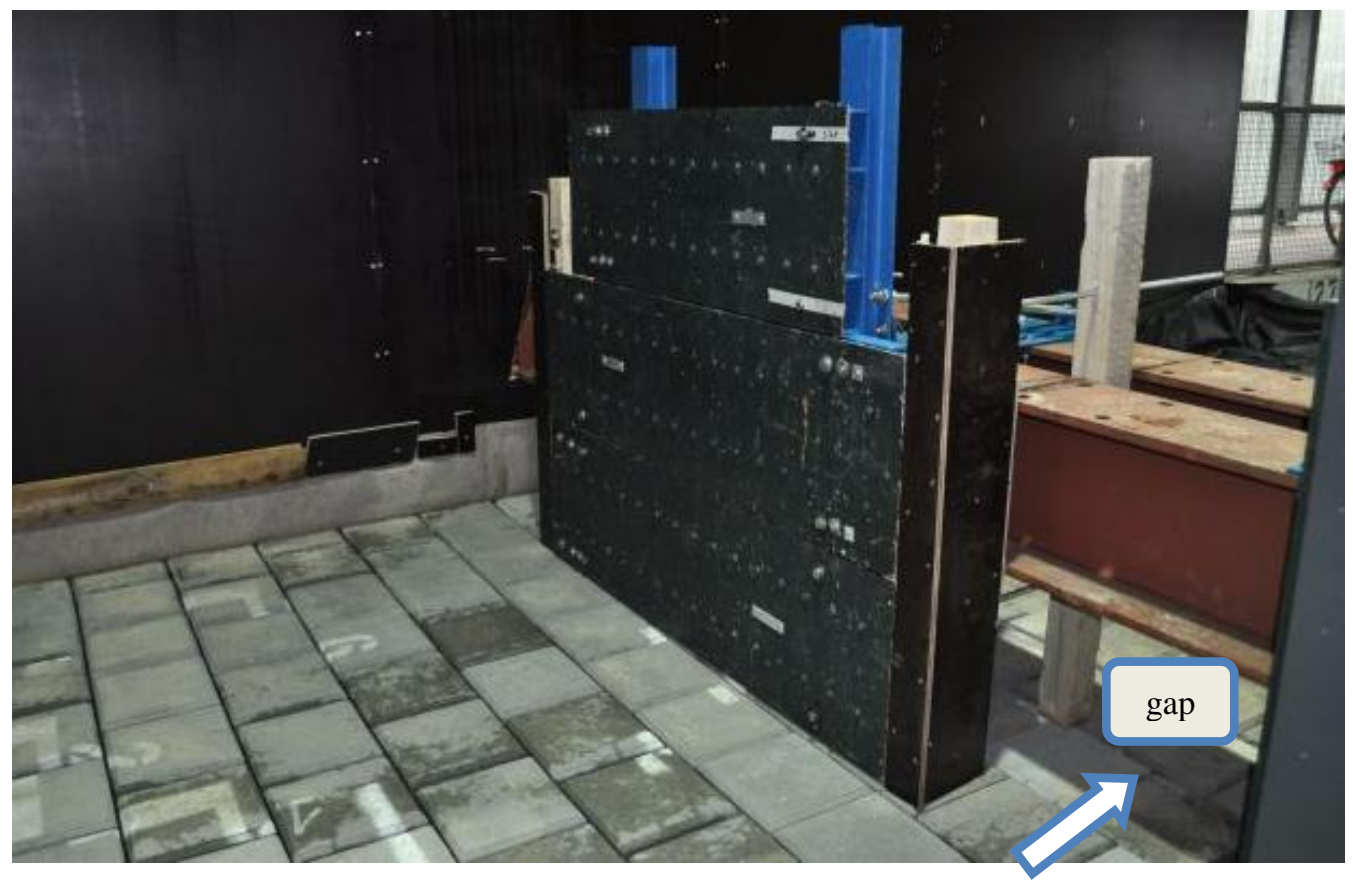

Fig. 6. The left storm wall, flanked by a $10 \mathrm{~cm}$ wide timber plate for minimizing the side effect.

\section{Measuring flow depths and flow velocities.}

Even by creating some gaps in between the storm walls, the bore hitting the wall itself, will always reflect. Some interaction with the next incoming overtopping bore will always occur. Unlike in the wave flume, where incoming wave parameters can be separated from the reflective ones, this can not be done here on the crest since it are not mathematically describable waves but a turbulent overtopping bore. In some cases, the overtopping waves are separated in time, which allows an analysis of the flow depth and flow velocity (see Fig. 7, left). In other cases, where the reflecting water is clearly interfering with the incoming bore, it becomes very difficult to analyze the flow parameters (see Fig. 7, right). Thereby, it was decided for this analysis, to only investigate the discrete overtopping bores, and the first waves of a group of overtopping bores. They will give the highest impacts, leading to a conservative design approach.

In Fig. 7, mainly on the left graph, one can also see the wave progressing and reflecting on the promenade. First a signal is recorded by the first digital step gauge (blue), then the $2^{\text {nd }}$ flow depth meter (red) responds, a few milliseconds later the $3^{\text {rd }}$ flow depth meter (green) responds. Shortly after, reflection occurs and the flow depth meters respond in reversed order (green, red, blue) indicating the reflecting bore. 

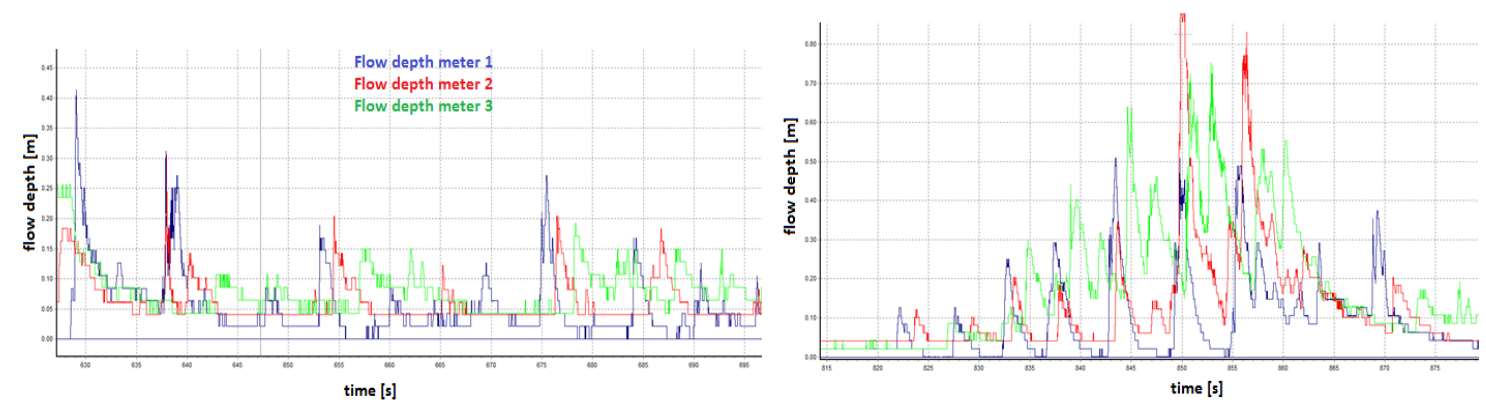

Fig. 7. Recordings of the flow depth meter: clearly separated overtopping bores (left) and large interference with reflection (right)

As was mentioned before, the flow velocity can also be determined from the time signals of two or more digital step gauges, see Fig. 8. Dividing the distance interval by the time difference in between two signals leads to the flow velocity in between the two considered flow depth meters.

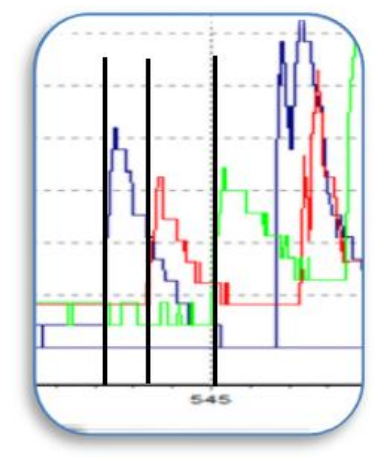

Fig. 8. Time interval between the flow depth recordings, with known distance interval between the sensors

Due to the difficulties with reflection and the failure of the velocity propellers, this is the best but most time consuming way to determine the velocities of discrete overtopping bores (no groups!) at certain points on the crest. This method implicitly assumes that the flow velocity is constant in between the 2 step gauges: $v_{12}$ between step gauge 1 and $2, v_{23}$ between step gauge 2 and 3 . This is not fully correct, but due to the short distance interval in between the step gauges, it can be accepted. This method is also used by Schuttrümpf and Oumeraci (2005) to calibrate their velocity meters at the crest of an overtopped dike. That paper works out a theoretical way to define the flow depths and flow velocities of an overtopping bore, and compares the theoretical formulae with experimental results. Table 1 shows a worked out example for the geometry of the dike and wave conditions used in this project: slope $\tan \alpha=1 / 3$, crest freeboard $R_{C}=1.5 \mathrm{~m}$, wave height $H_{S}=1.2 \mathrm{~m}$ and wave period $T_{P}=$ 10s. The formulas to calculate flow depth and flow velocity on the crest of a dike are described in Schuttrümpf and Oumeraci (2005):

$$
\begin{aligned}
& \frac{h_{c}\left(x_{c}\right)}{h_{c}\left(x_{c}=0\right)}=\exp \left(-0.75 \cdot \frac{x_{c}}{B}\right) \\
& \frac{v_{c}\left(x_{c}\right)}{v_{c}\left(x_{c}=0\right)}=\exp \left(-0.5 \cdot \frac{x_{c} \cdot f}{h_{c}}\right)
\end{aligned}
$$

where $x_{c}$ is the distance at the crest, $B$ is the crest width $(10 \mathrm{~m}), f$ the friction of the slope $(0.02$ for smooth slopes) and $h_{c}$ and $v_{c}$ are the flow depth respectively flow velocity at the crest. The decrease in flow depth is related to the distance along the crest, while the decrease in flow velocity is depending on both the distance along the crest and the flow depth at that position. 


\begin{tabular}{|c|c|c|c|c|}
\hline \multicolumn{5}{|c|}{ Table 1. Flow depth and flow velocity on the dike, for wave conditions Hs = 1.2m, Tp = 12s } \\
\hline $\begin{array}{l}\text { Distance at crest } \\
\text { (position of sensors) }\end{array}$ & Flow depth & $\begin{array}{l}\% \text { difference } \\
\text { with previous }\end{array}$ & Flow velocity & $\begin{array}{l}\% \text { difference } \\
\text { with previous }\end{array}$ \\
\hline $0 \mathrm{~m}$ & $0.673 \mathrm{~m}$ & & $6.8 \mathrm{~m} / \mathrm{s}$ & \\
\hline $0.5 \mathrm{~m}$ & $0.648 \mathrm{~m}$ & $-3.7 \%$ & $6.75 \mathrm{~m} / \mathrm{s}$ & $-0.8 \%$ \\
\hline $3.8 \mathrm{~m}$ & $0.505 \mathrm{~m}$ & $-21.1 \%$ & $6.31 \mathrm{~m} / \mathrm{s}$ & $-6.4 \%$ \\
\hline $7.9 \mathrm{~m}$ & $0.372 \mathrm{~m}$ & $-19.9 \%$ & $5.5 \mathrm{~m} / \mathrm{s}$ & $-11.9 \%$ \\
\hline
\end{tabular}

This decreasing trend can also be seen from both Fig. 7 and Fig. 8 for a discrete overtopping bore, where both the flow depth and flow velocity are reducing when propagating over the crest. The reduction factors in Table 1 are however not calculated for the exact same wave conditions of the wave that created wave overtopping and flow depth recordings from the Fig. 7 and Fig. 8. The values in Table 1 thereby don't correlate exact with Fig 7 and 8, but a similar descending trend is clearly visible.

Since the dike was built of concrete tiles with small gaps in between, the structure was not complete impermeable; the friction factor might be a little bit higher than the 0.02 assumed. Thereby, the values in Table 1 are a little higher then what was measured on the crest during the experiments.

The double descending trend in both flow depth and flow velocity seems to be in contradiction to the continuity equation. However, if the integral of the product of $h(t)$ and $v(t)$ over time is taken, continuity equation will be fulfilled. The reduction is due to the dispersion of the overtopping bore over the crest, and the friction along the bottom surface (Schuttrümpf and Oumeraci, 2005).

\section{ANALYSIS}

\section{Force measurements}

Force sensors are recording the response of the structure to the impact of the overtopping bore. Both the left (horizontal) storm wall and the right part of the right (vertical) storm wall are equipped with force sensors. The storm wall is made of an aluminium plate, stiffened by steel beams, which is attached to the force sensors by M16 screws. There is one force sensor in the corner of each individual plate, see Fig. 4. The force recording of each sensor includes a certain area of the plate. To quantify the magnitude of the total impact, the recordings of all force sensors per plate have to be summed. The left (horizontal) storm wall consists of 3 plates, two with a width of $1.7 \mathrm{~m}$, the top one has a width of $1.3 \mathrm{~m}$. The right (vertical) storm wall is only $0.5 \mathrm{~m}$ wide. To be able to sum the 3 horizontal plates, and also to be able to compare horizontal and vertical storm wall, forces have to be expressed per meter in width. The ratio between the forces on the individual horizontal plates, or the ratio between the bottom and top sensors on the vertical wall already give an indication of the force distribution over the height.

Fig. 9 shows a force recording over time for 1 test (20110623_06) of 2 individual sensors (blue color, located on the bottom left of the lowest horizontal plate; green color, bottom right), together with the sum of all 12 force sensors on the horizontal wall (red color). All forces are expressed in $\mathrm{kN} / \mathrm{m}$. The blue and green lines are very similar, and together they represent the largest share of the total force. This means the application point of the impact is located near the bottom of the storm wall. 


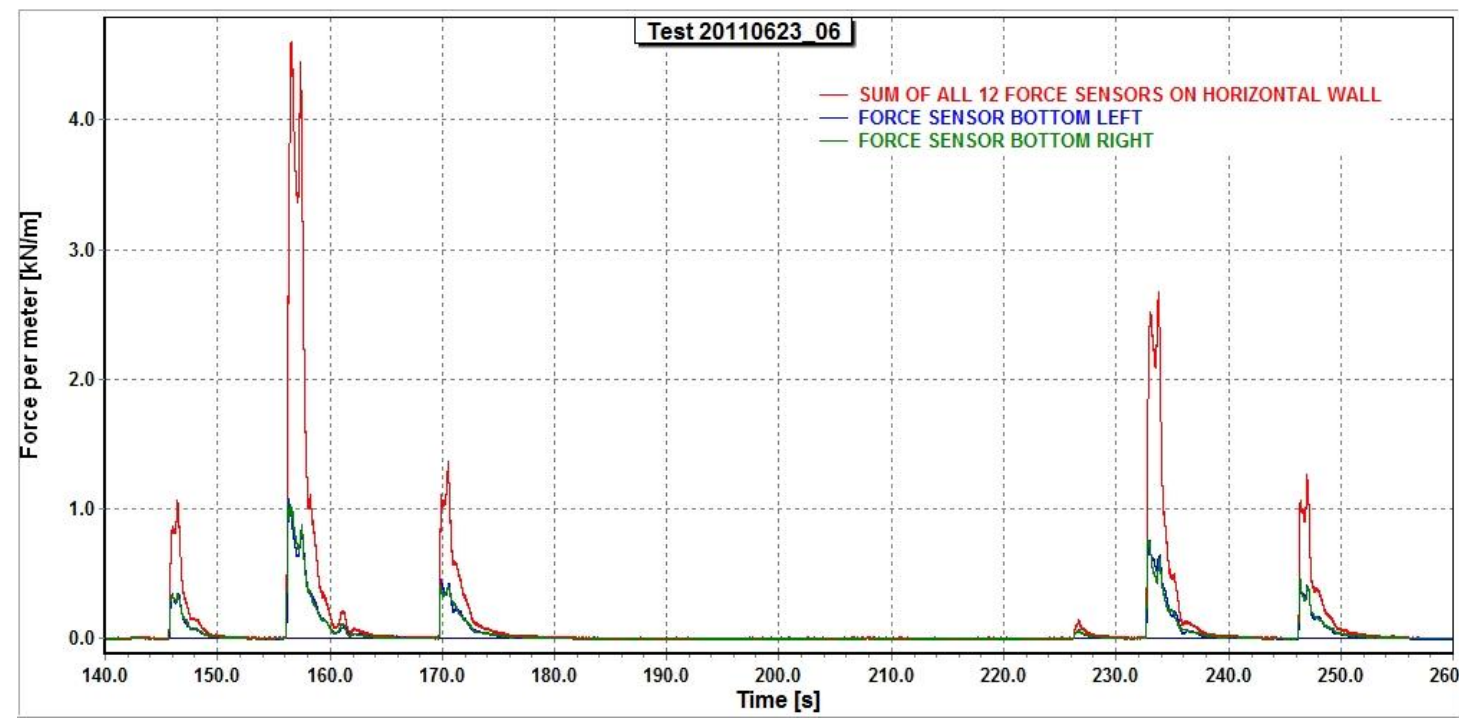

Fig. 9. Force recording of test 20110623_06 in a time interval of 120s: red = total force, blue $=$ force recorded by sensor bottom left, green = force recorded by sensor bottom right. Forces expressed in kN/m.

Fig. 10 zooms in on the highest impact during that same test. A steep rise of the signal shows the dynamic part, while the $2^{\text {nd }}$ peak is the quasi-static force due to the maximum run-up. This will be shown in more detail with the pressure measurements.

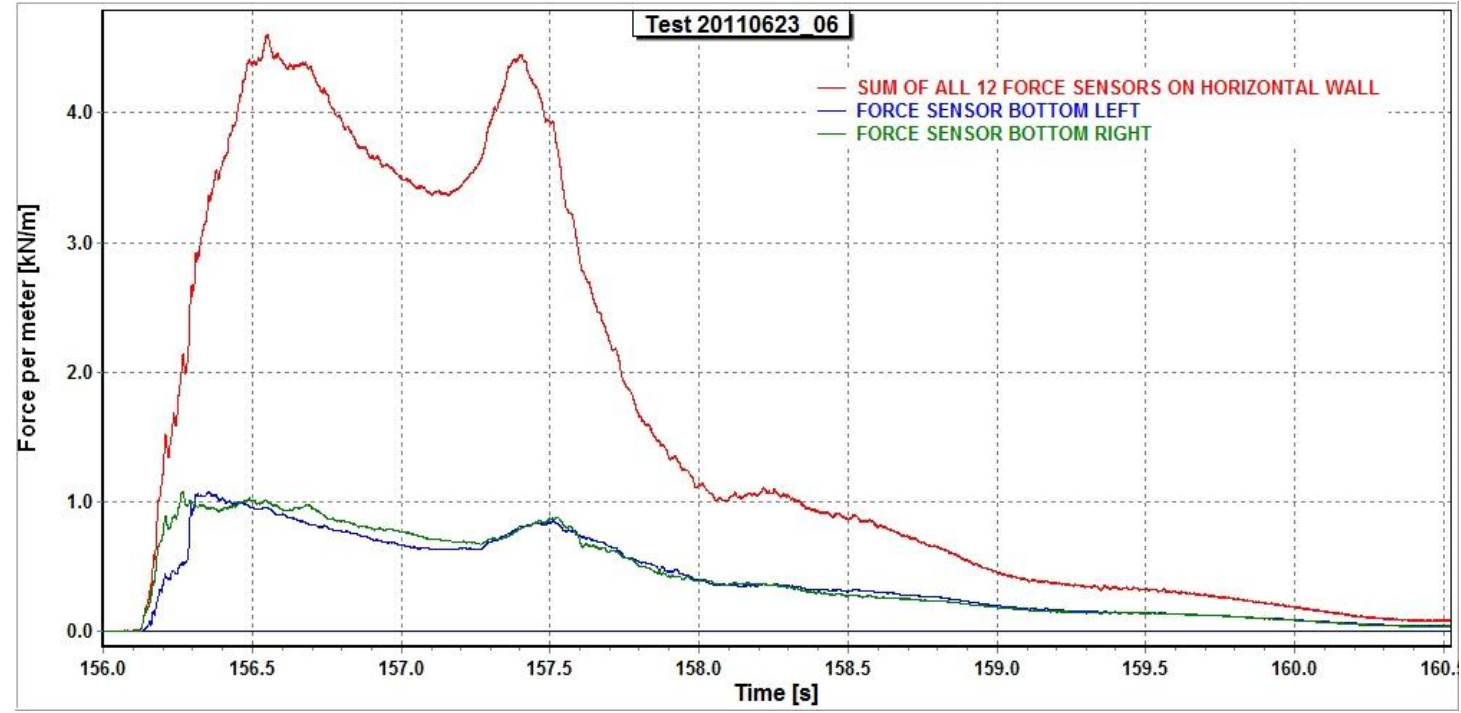

Fig. 10. Detail of the highest peak of Fig. 9: a first peak (hydrodynamic force) followed by a second peak (quasi-static impact force)

\section{Pressure measurements}

Unlike the force sensors, who measure the response of the structure, the pressure sensors measure the impact of the overtopping bore itself. The location of the 8 sensors is shown in Fig. 4. A smaller interval near the bottom of the plate, and a constant $20 \mathrm{~cm}$ interval from sensor 3 to the top. Compared to the measurement with force sensors, this method will give a more precise view of the force distribution over the height.

When integrating the pressure sensors over the height, a total force per meter in width is obtained. Fig. 11. shows the counterpart of Fig. 10, but this time for integrated pressures instead of direct forces, measured at the same impact (highest impact of test 20110623_06): in blue the highest loaded individual sensor is shown, in red the total integrated pressures are shown. 


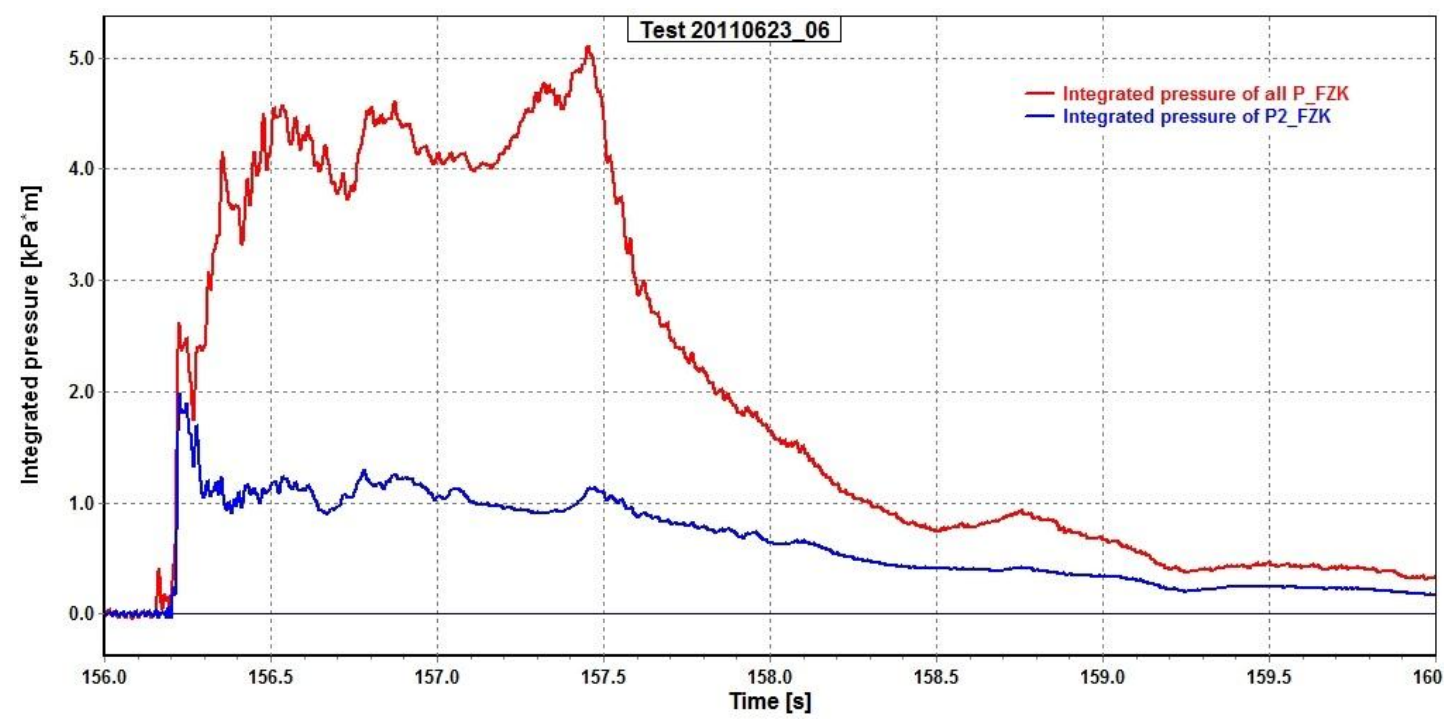

Fig. 11. Pressure the same impact as in Fig. 10, this time of the recorded pressures: total integrated pressure in red, pressure on highest loaded sensor P2 in blue.

In Fig. 11, a rectangular method of integration, as explained in Ramachandran et al., is used. This assumes a constant pressure in between two sensors. If a trapezoidal integration is applied, results are the same. This means the interval between the sensors was small enough to come to a realistic force distribution.

Most force and pressure recordings of a wave impact show a church roof profile with a clear difference between the high dynamic peak and lower second peak, the quasi-static peak. In this case, where an overtopping bore with a certain volume is impacting the structure, a longer supply of incoming water takes place leading to wave run-up along the storm wall which maintains much longer than the hydrodynamic peak. A larger quasi-static peak is observed.

The hydrodynamic peak in Fig. 11 occurs at 156.225s, the quasi-static peak at 156.458s. If the pressure values of all sensors are plotted at those two moments, the distribution over the height is shown at moment of the hydrodynamic and quasi-static peak, see Fig. 12 left and right. The hydrodynamic peak (Fig. 12, left) is clearly due to the wave impact: the water layer $(42 \mathrm{~cm}$ for this overtopping bore) impacts at the bottom 3 sensors. The quasi-static peak (Fig. 12, right) is due to the maximum wave run-up. A quasi hydrostatic pressure profile is to be seen.
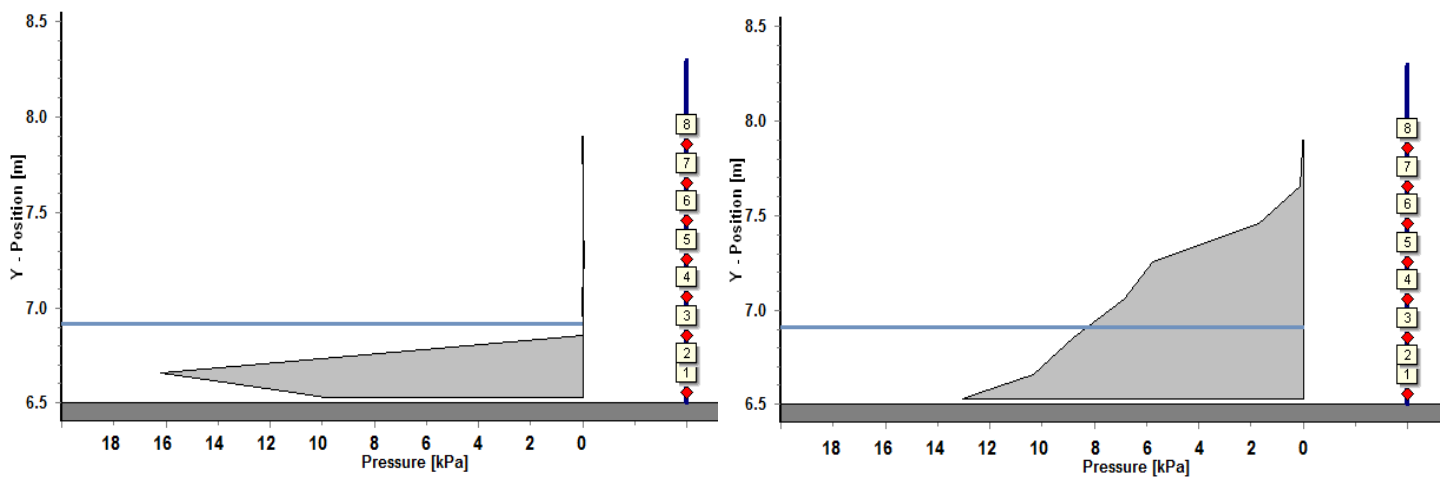

Fig. 12. Pressure distribution of hydrodynamic peak (156.225s, left) and of quasi-static peak (156.458s, right) 
Comparison between pressures and forces

As can already be seen from Fig. 10 and Fig. 11, the maximal value of the pressure integration $(5.0 \mathrm{kN} / \mathrm{m})$ is a little higher than the maximal value of the force recording $(4.4 \mathrm{kN} / \mathrm{m})$. When having a closer look at both signals (Fig. 13), the pressure recording over time is always a little higher than the forces but the overall shape and offset is the same.

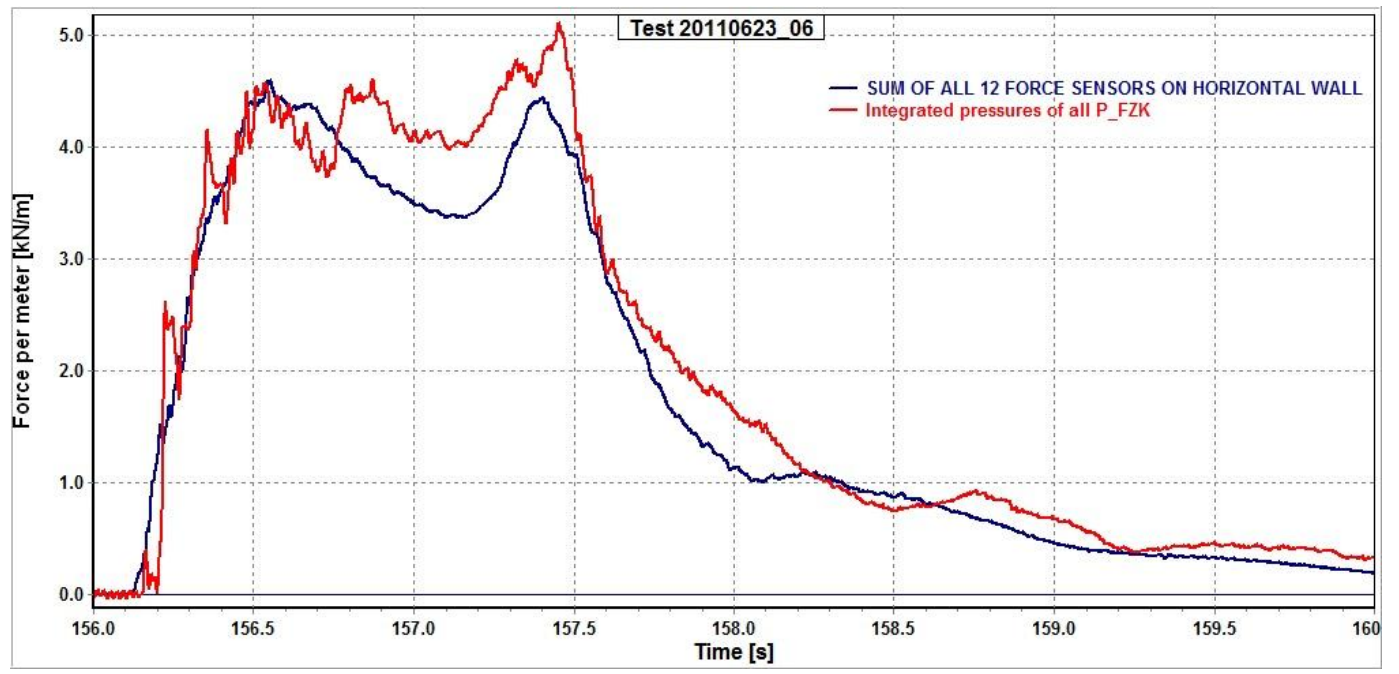

Fig. 13. Direct force measurement (blue) and force measurement by integrating pressures (red), comparison of the highest impact

This result was also found for the regular waves in case of a partially blocked storm wall (gaps in between to let the water evacuate). Several reasons for this difference can be found, some of them are also described in Ramachandran et al. (2012)

- Pressure sensors measure the impact, and are not dependent on the structure. The force measurements on the other hand might be a little influenced by the structure: stiffness, reaction time, ...However the stiffness of the whole supporting structure was very high.

$\circ$ The pressure sensors have a smaller measuring surface. If a local peak value in the turbulent bore, which is characterized by spatial pressure variations, hits this smaller surface, a high value can be recorded. In case of force sensors this high values will be smoothened out since you measure over a wider surface

- There is some energy loss due to water evacuating through the gaps. The force sensors, measuring a certain area, are possibly a little more influenced by this than the smaller pressure sensors which are located further away from this gap.

- In some cases, when the reservoir was full and overflowing back towards the storm walls, a residual water layer behind the storm walls was noticed. This exerts a hydrostatic force component on the wall in the opposite direction, which reduces the measured total force. Pressure sensors were not influenced by this.

Despite this many possible reasons, the integration of pressures and forces correspond quite well. Fig. 14 gives a scatter plot of the maximal force peak and maximal integrated pressure peak of each impact of all analyzed tests. As can be seen, the higher the impact larger the difference between the integrated pressure and the direct force measurements become. 


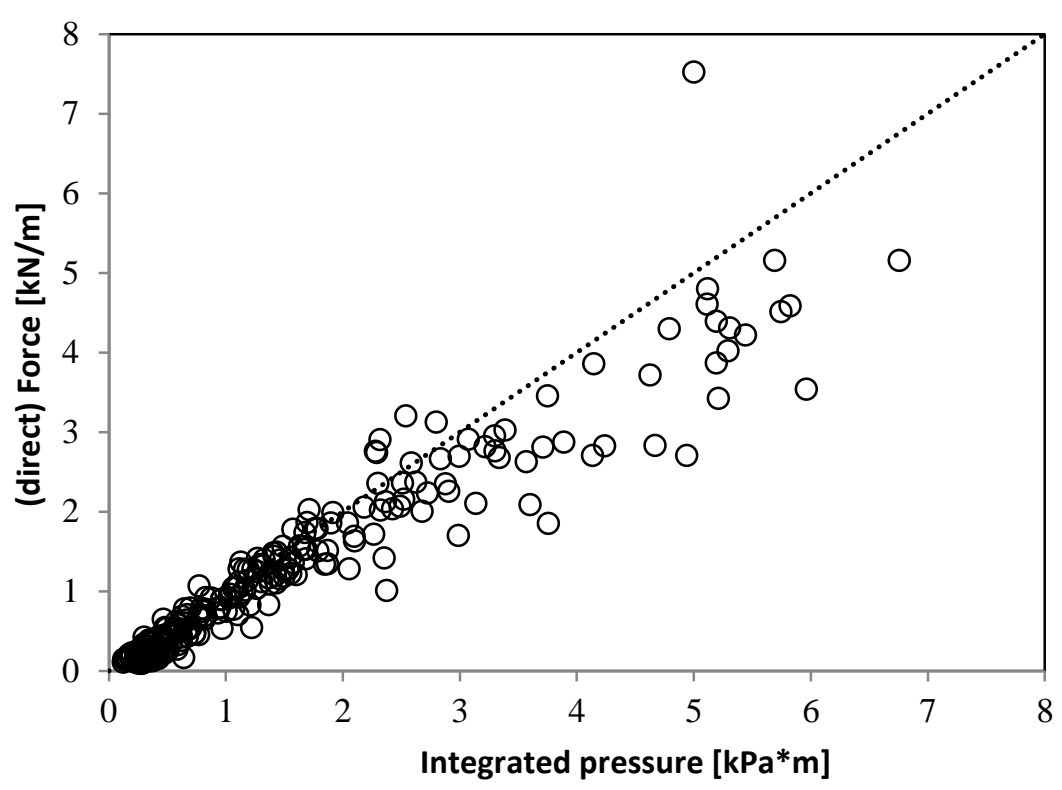

Fig. 14. Direct force measurements compared to integrated pressures, plotted together with the $45^{\circ}$ line.

Influence on the width of the plate on the force measurements

Since 2 different wall setups were installed, the results on the left (horizontal) storm wall and the right (vertical) storm wall can be expressed per meter width and compared. Fig. 15 shows this relationships for all tests, and no big difference is to be seen. Points are located around the $45^{\circ}$ line.

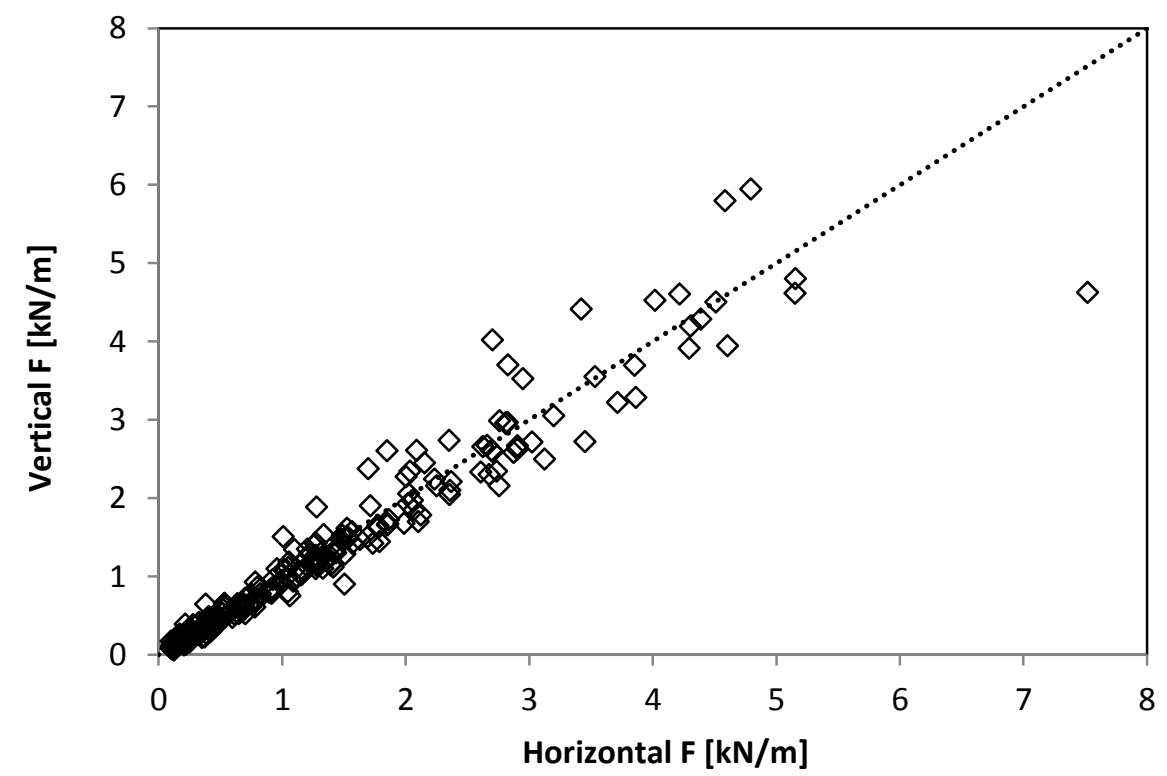

Fig. 15. Comparison between forces on left (vertical) wall and right (horizontal) wall, plotted with the $45^{\circ}$ line.

\section{Impacts related to overtopping bore parameters}

As was explained in the beginning of this paper, only discrete overtopping bores and the first bore in a group of overtopping waves are considered in this analysis. The flow depths of the digital step gauge closest to the storm wall (LT3) is considered, together with velocity $\mathrm{v}_{23}$ in between LT2 and LT3. When the flow velocities $v_{23}$ of all analyzed overtopping bores of all tests are then plotted versus the integrated pressure, a lot of scatter appears, see Fig. 16 (left). To explain this scatter, a detailed view on the flow velocity $v_{23}=4.10 \mathrm{~m} / \mathrm{s}$ is shown, where also the values of the flow depths (Fig. 16, right) are given. The increasing impact force is directly related to an increasing flow depth at constant velocity. 


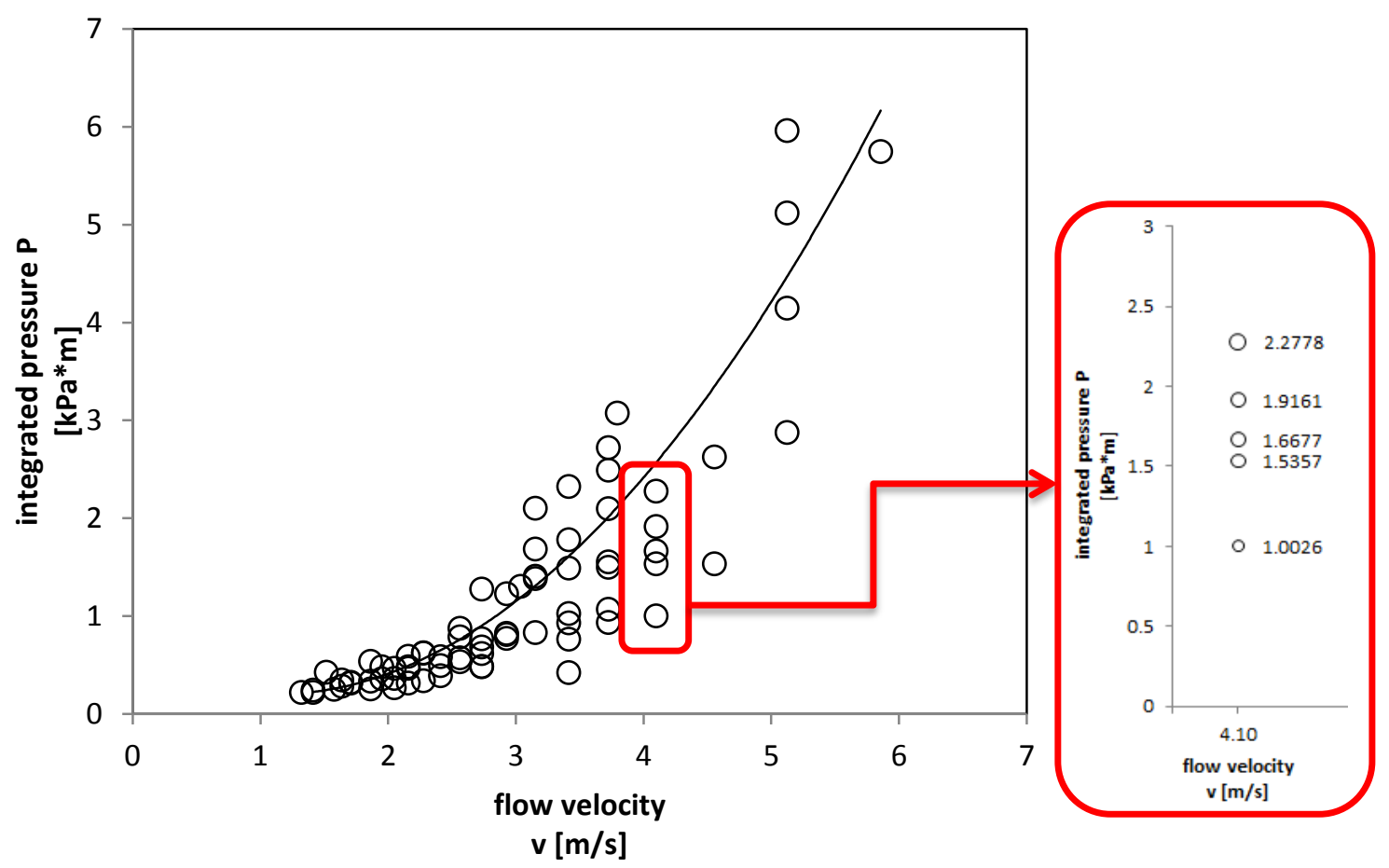

Fig. 16. Total force as a function of the flow velocity (left part). Increasing flow depth for a constant velocity (right part)

If we plot the opposite, flow depth versus impacts, a similar graph appears: for one flow velocity, the impact force increases with increasing flow depth.

This graph shows that the impact force is related to both flow depth and flow velocity. If both parameters are multiplied, $v(\mathrm{t}) \mathrm{xh}(\mathrm{t})$, the overtopping discharge $\mathrm{q}(\mathrm{t})$ is obtained $\left(\mathrm{m} / \mathrm{s} \cdot \mathrm{m}=\mathrm{m}^{3} / \mathrm{m} / \mathrm{s}\right)$. A good relationship between impact force and overtopping discharge is shown in Fig. 17 for all analyzed overtopping bores in all available tests with irregular waves. Since no good velocity recordings were found, the manually calculated velocities are multiplied with the peak value of the flow depths, giving some kind of instantaneous maximal overtopping discharge.

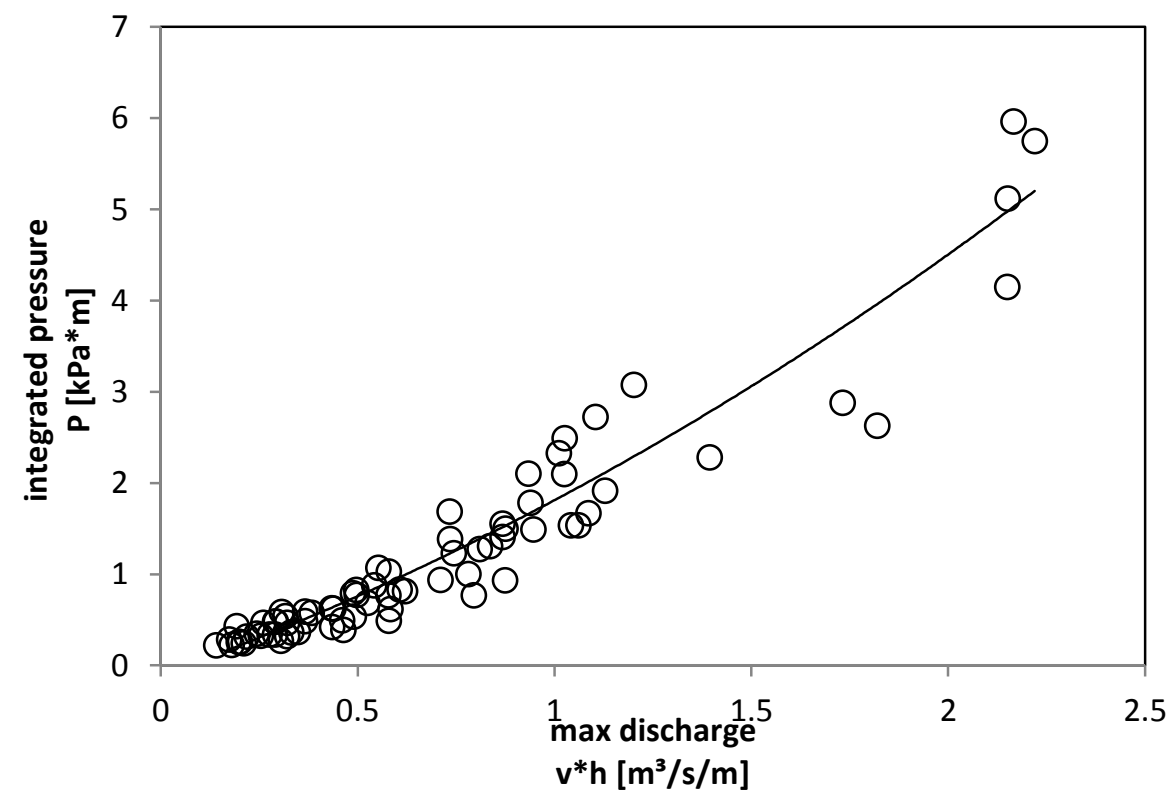

Fig. 17. Maximum forces on a plate (integrated pressures) as a function of the instantaneous maximal overtopping discharge measured at LT3. 


\section{CONCLUSION AND FUTURE RESEARCH}

Design formulae for wave impacts on vertical breakwaters can not be used to calculate the impact of post-overtopping bores on a storm wall. Experimental research was carried out, and the parameters of the overtopping bore were measured and linked to the impacts on a storm wall. A link between the wave conditions near the toe of the dike, the flow depth and flow velocity on the crest of the dike, and impact forces on the storm wall is to be analyzed in the near future. This paper mainly describes some general findings.

The force and pressure recording of overtopping bore impacts give a church roof profile, with a larger second peak compared to the case of impacting waves. The wave run-up along the storm wall lasts longer than the normal upward splash in case of impacting waves, and an increase in quasi-static force is clearly visible in the pressure distributions over the height of the storm wall.

Integrated pressures over the height are compared with direct force measurements, and when both are expressed in $\mathrm{kN} / \mathrm{m}$, it was noticed that pressure measurements give a little higher values than direct force measurements. Some reasons for this difference are given in this paper, but the difference in between both measuring techniques is overall not that large.

Forces on two storm walls were measured, with a different geometry of the storm walls. However, if the forces on these two geometries are expressed in $\mathrm{kN} / \mathrm{m}$ and compared, no clear difference was noticed. The width of the storm wall used for the experiments has no clear influence on the results.

When relating the impact to the flow depth or flow velocity, quite a lot of scatter appears. When having a closer look, it seems that only one parameter is not enough to describe the impact force. Both flow depth and flow velocity are causing the magnitude of the impact force. The overtopping discharge is a better parameter to relate to the impact forces. Since no velocity recordings over time, $v(t)$, were available, forces had to be related to a maximal overtopping discharge, and no average overtopping.

This research project will have a sequel in the Hydralab IV program, to be carried out in the Large wave flume CIEM at UPC Barcelona. For this project, it will be important to have a good design of the geometry and the measurement equipment in order to measure relevant parameters. The crest height of the wall should be a little lower than in GWK, and the overtopping basin and pump capacity should be larger. This would create more wave overtopping, but without having to stop the test due to a full overtopping basin. Longer tests series can then be carried out, and more statistics can be obtained.

The measurement of the flow velocity is another issue that should be improved. A way to determine incoming flow velocities and their velocity profiles over time is a challenge for the upcoming Hydralab IV project.

\section{REFERENCES}

Geeraerts, J., De Rouck, J., Beels, C., Gysens, S. and De Wolf, P. (2006) Reduction of wave overtopping at sea dikes: stilling wave basin (SWB). Proceedings of ICCE 2006, San Diego, USA.

Gier, F., Schüttrumpf, H., Lorke, S., Mönnich, J., Beton, B., Van der Meer, J. Stability of Interlocked Pattern Placed Block Revetments. Proceedings of ICCE 2012, Santander, Spain.

Mertens, T.; De Wolf, P.; Verwaest, T.; Trouw, K.; De Nocker, L.; Couderé, K. 2008. An integrated master plan for Flanders future coastal safety. Proceedings of ICCE 2008 Hamburg, Germany.

Ramachandran, K., Roldan Genzalez, R., Oumeraci, H., Schimmels, S., Kudella, M., Van Doorslaer, K., De Rouck, J., Versluys, T. and Trouw, K. Loading of Vertical walls by overtopping bores using pressure and force sensors. A large scale model study. Proceedings of ICCE 2012, Santander, Spain. (2012 a)

Ramachandran, K., Roldan Genzalez, R., Oumeraci, H., Schimmels, S., Van Doorslaer, K. Impact loads on a vertical wall due to overtopping bore - large scale physical model experiments. Proceedings of Coastlab 2012, Ghent, Belgium. (2012 b)

Steendam, G.J., Peeters, P., van der Meer, J.W., Van Doorslaer, K., Trouw, K. Destructive wave overtopping tests on Flemish dikes. Proceedings of Coastal Structures 2011, Yokohama, Japan

Schuttrümpf and Oumeraci. Layer thickness and velocities of wave overtopping flow at seadikes. Coastal Engineering 52 (2005) 473 - 495.

Van Doorslaer, K. De Rouck, J., Boderé, T., Vanhouwe, G., Troch, P., 2010. The influence of a berm and a vertical wall above SWL on the reduction of wave overtopping. Proceedings of Coastlab 2010, Barcelona, Spain. (2010 a)

Van Doorslaer, K., De Rouck, J. (2010) Reduction of wave overtopping on a smooth dike by means of a parapet. Proceedings of ICCE 2010, Shanghai, China (2010 b)

Van Doorslaer, K., De Rouck, J., Trouw, K., Van der Meer, J.W., Schimmels, S. Wave forces on storm walls, small and large scale experiments. Proceedings of COPEDEC 2012, Chennai, India. 